\title{
University Pedagogy:
}

\section{A New Culture is Emerging in Greek Higher Education}

\author{
Katerina Kedraka $^{1} \&$ Georgia Rotidi ${ }^{1}$ \\ ${ }^{1}$ Department of Molecular Biology \& Genetics, Democritus University of Thrace, Greece \\ Correspondence: Katerina Kedraka, Assistant Professor, Department of Molecular Biology \& Genetics, Democritus \\ University of Thrace, Greece. Dragana, Alexandroupolis - 68100, Greece.
}

Received: May 3, 2017

doi:10.5430/ijhe.v6n3p147
Accepted: June 6, 2017

Online Published: June 8, 2017

URL: https://doi.org/10.5430/ijhe.v6n3p147

\begin{abstract}
The aim of this paper is to highlight University Pedagogy as a field that focuses on academics' teaching role in Greek higher education. EU has recognized the need of improvement of the teaching skills of academics and urges the member states to recognize them as an important element of their professional profile. Only recently academics in Greece have launched the debate on innovative teaching and learning methods and practices. A Symposium that took place in 2016 and a significant empirical research are presented, because they are considered to mark the beginning of an emerging university culture, which incorporates the concern on teaching and learning excellence within higher education approaches in our country. The results of these initiatives indicate that critical self-reflection on teaching can lead to the transformation and to the adoption of alternative teaching practices, since the critically reflective process is a crucial point for the enhancement of an academic's pedagogical, curricular and instructional knowledge.
\end{abstract}

Keywords: University, Pedagogy, Greece, Academia

\section{Introduction}

Teaching and research are the two pillars of higher education in Europe, although still remains under question their exact relationship. Until the late $19^{\text {th }}$ century teaching was the most important function of universities, but during the $20^{\text {th }}$ and mostly in the $21^{\text {st }}$ century, research has become a primary concern for academics, while teaching was downgraded as a secondary activity. The debate on the teaching efficiency of academics is not new: it lies on the unequal interest of instruction versus research, as reflected in their promotion during their academic career. What really counts is not the improvement of their teaching skills but their research. As a result they rather underestimate their pedagogical role but they remain extremely active in publishing in scientific journals or submitting projects with remarkable budgets (Felder, 2004). However, due to the rapid demand for higher education in the last few decades, it seems that the importance of teaching is reviewed and reassessed in Greece and a pedagogical culture is launching in academia (Zondanos, 2011).

\section{University Teaching and Learning: A Theoretical Framework}

University Pedagogy could be accessed through the complex and intricate phenomenon of learning in higher education, taking into account the necessity to involve reflection and critical thinking. Reflection on teaching in higher education, though poorly understood, as Kreber (2205) argues, lies on three kinds of reflection: on content, process and premises. She proposes that academics should focus on three axes of knowledge regarding their teaching: instruction, pedagogy, and curriculum and could be investigated through her proposed model based on Mezirow's transformative learning theory. Transformative learning theory by Mezirow $(1991,2009)$ points out not only on the traditional character of instrumental learning (referring mainly to the acquisition of knowledge) but on transformative learning, ie the process of critically approaching, synthesizing and applying the acquired knowledge, so that learners develop critical thinking and skills to evaluate the methods, the knowledge and attitudes they acquire through their studies. According to Illeris (2007) learning in higher education lies on three dimensions: the content (including areas like curriculum/knowledge, teaching methodologies, development of basic skills and specially the one of critical thinking), the incentive (that is the emotional part of teaching, deriving from the relationships between teachers and students) and the interaction between the university and the local community, as part of the broader socio-economic environment. When a professor uses modern learning theories as a framework 
for instruction, he aims to lead students to learn how to approach critical thinking, how to collaborate and share tasks, present and defend their opinions, self-assess and evaluate others. Kokkos (2016) argues that transformative as well as holistic learning, could lead to a more, effective teaching in universities, "since the dimension of content within the framework of higher education is related to critical thinking and the use of experiential teaching methodologies" (p. 40). Recent research on teaching and learning in higher education focuses on the importance of the student-tutor relationship and the relevant emotions involved in learning (Karagiannopoulou, 2016). Kordts-Freudinger (2017) explores the cognitive regulation of tutors' emotions and confirms that approaches to teaching are based on emotional variables and that teaching could be understood as an emotional experience. In the same context, there is a growing research interest in exploring the relationship between the emotions of the teachers and the teaching approach they adopt (Trigwell, 2012).

Lynch and Pappas (2017) propose that professors should use various methods and techniques in order to stimulate students' interaction, critical thinking and active learning and they argue that even in large classes a "small class feeling" could be achieved, by following their model developed for active teaching in higher education. Winestone and Millard (2012) describe active learning as "meaningful learning activities that require higher-order thinking and the development of skills over the mere transfer of information" (p. 34) in order to lead to a fruitful assessment defined as the "information communicated to a learner that is intended to modify his or her thinking or behaviour for the purpose of improving learning" (p. 32). The authors propose that active learning -especially in large classes- can be beneficial for both students and teachers in terms of their learning engagement and outcomes, whereas Weaver and Qi (2005) underline that "active participation" is essential for learning and actually depends on students' participation. Accordingly, Prosser and Trigwell (2014) in their analysis argue that students are "more likely to adopt surface approaches to study if their teachers are adopting less of a conceptual change and a less student-focused approach to teaching" (p.791). Hornsby and Osman (2014) point out that the teacher-focused learning model leads to information transmission whereas a conceptual change towards a student-focused model should be adopted when it comes to "challenging students to think deeply, critically and creatively" (p. 716). Kivunja (2015) adds that the incorporation of technology in modern learning approaches is necessary and argues that selected social media technologies, if properly planned and implemented, could act ccomplementarily to pedagogical practices, because they support learning activities and the overall academic outcomes, such as high participation, interpersonal interactions among participants, metacognitive skills, peer mentoring, motivation and considerable student engagement.

Kedraka and Dimasi (2015) refer to the importance of University Pedagogy, which although has been highlighted in the educational legislation since the 19th century (!), still, nowadays, is not operating satisfactorily and although the Greek Ministry of Education has recently launched initiatives to improve the pedagogical competence of primary and secondary education teachers, nothing has been provided for higher education's teaching staff. The authors argue that the majority of Greek academics are not trained on Pedagogy and Didactics. Kedraka and Dimasi (2015) argue that the majority of Greek academics are not trained on teaching methods, while Gougoulakis and Economou (2014, 2016) consider University Pedagogy as a multidimensional process that also deals with specific teaching practices and approaches concerning the design, implementation and evaluation of learning processes that academics should follow within their role. Gougoulakis and Economou $(2014,2016)$ attempted a comprehensive approach to University Pedagogy, defining it as the implementation of pedagogical principles in higher education's institutions, answering to the main question: What kind of knowledge and skills should a university teacher possess in order to effectively facilitate students' learning and personal development? They argue that it integrates various pedagogical theories and approaches in the actual Greek higher education educational system, while it deals with teaching practices on the design, implementation and evaluation of learning processes. They underline, though, that academics should engage more actively within their teaching role in order to achieve better results in the area of instruction. At the same time it deals with issues deriving from counseling and educational psychology which enable an academic to best communicate and interact to his students. They also underline the need for pedagogical training of both the permanent teaching staff of higher education in Greece and their associates (postdoc researchers, Ph.D. candidates, scientific collaborators). Pantano-Rokou and Sakellaridis (2001) in their study argue that when Greek academics teach in different learning environments (especially in Distant and in Adult Education settings), then, they are transformed from "performers" into "architects" of the learning process, from "transmitioners" of knowledge to teachers-facilitators of the learning process. Obviously, university teachers have to add the pedagogical dimension to their professional profile, taking into account three parameters of their teaching role: implementation, interaction and teaching (Rossiou, 2010). Anastasiades and Karvounis (2010) reveal students' expectations for teachers with significant teaching competence, apart from his/her scientific expertise. 


\section{Current European Policies}

Since higher education is considered of particular importance for the progress of both individuals and societies, "good" university teaching is encouraged by European policies as it significantly contributes to socio-economic progress (Hunt, 2003). The importance of upgrading universities led the policy centers of the European Union to prioritize the goal of upgrading the status and implementation of teaching in higher education. European Commission in a document titled: Redesigning Education (European Commission, 2011) underlines the need to adopt innovative teaching approaches and methods in order to improve the quality and effectiveness of higher education. The document emphasizes that both research and teaching are important within the academic community, but teaching is considered as primarily responsible for impacting educational outcomes and the employability of graduates of European higher education institutes. The role of academics is identified as core and in order to achieve this mission, universities should encourage their competent academics and cutting-edge researchers, to invest on inspired instruction, too (Kedraka, 2016).

In 2013 European Commission set up a High Level Group (HLG) for the modernization of higher education (Note 1). The HLG made concrete proposals, urging policy makers of each Member State of EU and higher education institutions to promote the quality of teaching and learning, taking into account that universities usually pay less emphasis on teaching than on research. This study is considered as particularly important, because it points out the overweight focus on research versus teaching, within the European academic community, which has been taken for granted for a very long period of time, with all the negative consequences that could occur. Indeed, HLG's report titled: "Improving the quality of teaching and learning in Europe's higher education institutions" recognizes the major impact of University Pedagogy on the quality of higher education and sets instruction in universities at the key point for improving the quality of learning, pointing out that the challenge for higher education, is to professionalize its teaching staff as teachers.

\section{The Case of Greece}

This debate has reached Greek academia as well and an interest has been emerged on the importance of teaching in higher education. At this point, we have to note that research in Greece does not contain the issue of teaching in universities, although contemporary social trends, the use of new technologies in education and the ongoing developments in the field of pedagogy, challenge professors' teaching skills (Christou, 2014).

Due to the emerging interest on University Pedagogy in Greece, even at a later time comparing to the rest of the European or the international institutions, a first initiative was undertaken by the Democritus University of Thrace (Department of Molecular Biology and Genetics, Lab of Teaching and Job Skills of Bioscientists) by organizing a Symposium titled: "University Pedagogy: Education and teaching in higher education, a 'terra incognita'?" which took place in Alexandroupolis, 9-11 September 2016. The scope of the Symposium was to introduce a debate and a reflection among academics, regarding issues of critical thinking and of a holistic approach to teaching and learning processes in Higher Education in Greece. It was attended by experts, scientists and academics from several Greek and European universities. A significant result of this Symposium was the Network of academics that was built, which has a role to lead the scientific debate within the academic community of Greece, in order more attention is paid to the importance of teaching in the Greek universities. Therefore, it is expected to open up prospects for the launching of University Pedagogy in Greek higher education and to work on the development of three major thematic areas: (a) theoretical background, (b) institutional initiatives to be taken, and (c) practical teaching approaches, as well as necessary educational acts to fill in gaps on the academics' lack of formal pedagogical training. Already, as a first result of our efforts, we can mention the significant initiatives undertaken by two Greek universities (Democritus University of Thrace and University of Patras) towards the direction of empowering and training their academics on pedagogical issues.

This effort is considered important taking into account that Greece is still in the middle of an economic crisis, which has been turned into a social crisis as well, revealing among other severe consequences the "brain drain", that is the turning of great numbers of Greek students abroad, either for job seeking or for postgraduate studies, (Labrianidis and Vogiatzis, 2013). Although this phenomenon cannot be attributed only to the poor quality of studies, improving the teaching methods and processes used in higher education institutions, could be a persuasive argument for young people to stay and struggle for better studies and/or employment in our country.

\subsection{Clues for Teaching Patterns in Greek Universities}

Although research on University Pedagogy is poor regarding Greek higher education, as Karagiannopoulou (2016) argues, a most interesting research project on teaching patterns used by professors in higher education's institutions 
in Greece was carried out at the University of Patras, during the academic years 2011-2015 (Rotidi, 2016). The project explored the relationship between 114 Greek university professors' teaching perspective (from 15 Departments of 9 Universities), as detected by the use of Pratt and Collins' Teaching Perspectives Inventory (Note 2) -TPI- and their discipline, according to Biglan's (1973) classification in Hard and Soft, Pure and Applied fields. The study also examined the level of professors' critical reflection (Mezirow, 1991) underpinning their teaching perspectives with regards to three domains of their knowledge: Curricular (aims of teaching), Pedagogical (knowledge about teaching and learning processes) and Instructional (teaching practices). These domains -and their relation to the two aforementioned levels of critical reflection- were detected by Kreber and Cranton's SofT (Scholarship of Teaching) model (Kreber \& Cranton, 2000). Rotidi (2016) argued that a professor's discipline influences the adoption of certain teaching perspectives, given that student-centered teaching perspectives dominate mostly Soft/Applied and Soft/Pure disciplines. The term Soft disciplines in this study embraced the fields of Sociology, Linguistics, Philosophy, Economics, Educational Sciences and Law), while the teacher-centered teaching perspective (Transmission) dominated primarily the Hard/Soft and Applied fields (Sciences, Mathematics, Dentistry, Medicine, Computer Engineering and Informatics). Transmission teaching perspective was found to dominate all the four clusters of Greek academics' disciplines, mainly underpinning their beliefs about teaching and learning. Their teaching objectives scored higher on the developmental teaching perspective (student-centered) instead. The higher focus on transmission teaching perspective of the 114 Greek academics was reaffirmed by comparing their TPI profile with a similar international sample of 127 instructors drawn from the TPI database (Rotidi, Collins, Karalis, and Lavidas, 2017). In any case, one should take into consideration that the interpersonal differences, according to academics' TPI profile, outweigh the interdisciplinary ones., whereas the correlation of professors' beliefs, intentions and actions (the three components of a teaching perspective), according to both their dominant and back-up teaching perspectives, revealed that an academic's teaching perspective is multifocal, as Rotidi (2016) showed in her research.

Rotidi (2016) also found that critical reflection of assumptions (Mezirow, 1991), which is the highest level of critical reflection and the most important precondition for the transformation of a teaching perspective, was not common in any of the three knowledge domains of academics' knowledge (Kreber, 2004; 2005; Kreber and Castleden, 2009). Greek academics, mostly coming from Soft fields, provided evidence of premise reflection, more frequently observed within the domains of Pedagogical and Instructional Knowledge. Kreber and Castleden (2009: 527), citing Huber and Morreal (2002), argue that "the kinds of questions faculty have learned to ask about the knowledge of the discipline are, to an extent, a mirror image of the questions they ask about their teaching". This finding is probably also attributed to the student-centered teaching perspectives (or to the convergence of academics' intentions and actions towards these perspectives) dominating the Soft disciplines.

According to Rotidi's research (2016) Greek academics seem to give more evidence of process reflection for the domains of Pedagogical and Curricular than in Instructional knowledge (see also Rotidi and Karalis, 2014). We could consider this finding as an "intriguing" one, since the majority of the Greek academics has not received any formal training on teaching, this probably means that an academic develops his teaching patterns mostly through experience and reflection (Oleson and Hora, 2014). However, the lack of an extensive and well developed training on pedagogical knowledge and skills seems to be an obstacle to the use of any alternative teaching strategy and this lack probably explains the lower means of Greek academics on the domain of instructional than on the other two domains of their teaching knowledge (Rotidi, 2016).

\section{Conclusion}

Nowadays, more than ever, the teaching skills of an academic cannot depend on his/her talent, but in focused training provided within a broader context of university culture that approaches teaching as a pedagogical process that promotes active learning (Hannan and Silver, 2000). Current research in Greece indicates that an academic's convergent teaching perspective play a significant role in the way that engages reflection on the knowledge of how students learn and how a professor should facilitate learning. On the other hand, if it's true that "one size does not fit all" (Pratt, 2002), then insisting on the uniqueness of "good practice" in teaching, while asking academics to reflect critically on it, entails a false promise to differ from the prevailing perception on the effectiveness of student-centered teaching perspectives, that stems mainly from the reaction against the teacher-centered teaching model (Gibson, 2010), which has dominated higher education's literacy (Collins and Pratt, 2011).

It is high time that Greek academia takes a shift from teacher-centered methods to active learning processes, from the "what" to the "how" and "why" of their teaching, through the development of a university culture that faces learning as a profoundly pedagogical procedure, based on students' critical thinking, motivation and activation. It seems that University Pedagogy, an area built on a complicated picture of pedagogical skills, emotional interaction between 
professors and students and research innovations, modern technologies and approaches and critical learning could help towards this direction. This will be achieved in terms of: i) the development of empirical research in the field of University Pedagogy in Greece, ii) the implementation of critical reflection, active and experiential learning in universities and iii), communication and cooperation on sharing of interest, research and good practices with academics from all over the world. The need to do our best as academics is urgent, now, in recession times, struggling to stop the leak of young students, the most promising part of our population, who set their studies and lives abroad.

\section{References}

Anastasiades, P., \& Karvounis, L. (2010). Students' opinions in the postgraduate module EKP 65 "Open and Distance Education" for the role and the mission of the Tutor Counsellor in Hellenic Open University. Open Education - The Journal for Open and Distance Education and Educational Technology, 6(1\&2), 80-92. https://doi.org/10.12681/jode.9752

Biglan, A. (1973). Characteristics of subject matter in different academic fields. Journal of Applied Psychology, 57(3), 195-203. https://doi.org/10.1037/h0034701

Christou, K. (2014). The challenges for the Public University. Lecture in the meeting of the Central Committee of Education Office of AKEL titled: "Public University under threat", September 17, 2014. Cyprus: University of Cyprus. (in Greek)

Collins, J.B. \& D.D. Pratt, (2011). The Teaching Perspectives Inventory at 10 Years and 100,000 Respondents: Reliability and Validity of a Teacher Self-Report Inventory. Adult Education Quarterly, 61(4), 358-375. https://doi.org/10.1177/0741713610392763

European Commission, (2013). High Level Group on the Modernization of Higher Education. In: http://europa.eu/rapid/press-release_IP-13-554_el.htm). Report: Improving the quality of teaching and learning in Europe's higher education institutions is available on http://ec.europa.eu/education/higher-education/doc/modernisation_en.pdf/.

European Commission, Strasbourg COM (12) 669 final (2012). Redesigning of Education: investing in skills for better socio-economic results. In: http://www.europarl.europa.eu/

European Commission, Directorate General For Research \& Innovation, (2011). European Research Area Skills. In: http://ec.europa.eu/euraxess/pdf/research_policies/

Felder, R. (2004). Teaching engineering at a research university: problems and possibilities. Educación Química, 15(1), 40-42.

Gibson, R. (2010). The 'art' of creative teaching, implications for higher education. Teaching in Higher Education, 15(5), 607-613. https://doi.org/10.1080/13562517.2010.493349

Gougoulakis, P., \& Economou, A. (2014). University Pedagogy. Educ@tional cycle, 2(1), 9-48. In: http://www.educircle.gr/ (in Greek)

Gougoulakis, P., \& Economou, A. (2016). Pedagogical and didactic training of University teachers. Neos Pedagogos, 7, 74-90. In: http://neospaidagogos.gr/periodiko/ (in Greek)

Hannan, A., \& Silver, H. (2000). Innovating in higher education: Teaching, learning and institutional cultures. Buckingham: Society for Research in Higher Education.

Hornsby, D. \& Osman, R. (2014). Massification in higher education: Large classes and student learning. Higher Education: The International Journal for Higher Education and Educational Planning, 67, 711-719. https://doi.org/10.1007/s10734-014-9733-1

Hunt, L. (2003). What makes good university teaching? Improving Teaching and Learning in Universities. B-HERT NEWS, 18, 1-5.

Illeris, K. (2007). How We Learn: Learning and Non-learning in School and Beyond. London: Routledge.

Karagiannopoulou, E, (2016). Students' learning, academic environment and individual factors. A brief review of the relevant literature- links to Greek studies. Towards a new research tradition... In K. Kedraka (ed) (2016). Proceedings of the Symposium on University Pedagogy: Education and training in Higher Education, a terra incognita; 108-117. Alexandroupolis: Democritus University of Thrace. (in Greek). In: http://panepistimiaki-paidagogiki.gr/praktika/praktika2016.pdf 
Kedraka, K. (ed) (2016). Proceedings of the Symposium on University Pedagogy: Education and training in Higher Education, a terra incognita; Alexandroupolis: Democritus University of Thrace. (in Greek). In: http://panepistimiaki-paidagogiki.gr/praktika/praktika2016.pdf

Kedraka, K. (2016). University Pedagogy: Past, Present and Future. In K. Kedraka (ed) (2016). Proceedings of the Symposium on University Pedagogy: Education and training in Higher Education, a terra incognita; 21-39. Alexandroupolis: Democritus University of Thrace. (in Greek). In: http://panepistimiaki-paidagogiki.gr/praktika/praktika2016.pdf

Kedraka, K., \& Dimasi, M. (2015). Teaching in Higher Education: Obligation, burden or privilege? Proceedings of the 1st Experiential International Conference on Applied Teaching, Drama: November 2015. In http://www.educircle.gr/synedrio (in Greek)

Kivunja, Ch. (2015). Innovative Methodologies for 21st Century Learning, Teaching and Assessment: A Convenience Sampling Investigation into the Use of Social Media Technologies in Higher Education, International Journal of Higher Education, 4(2), 1-26, 199-212. https://doi.org/10.5430/ijhe.v4n2p1

Kreber, C., \& Castleden, H. (2009). Reflection on teaching and epistemological structure: Reflective and critically reflective processes in pure/soft and pure/hard.Higher Education, 57(4), 509-531. https://doi.org/10.1007/s10734-008-9158-9

Kokkos, A. (2016). Towards a multi-dimensional way of learning in Higher Education. In K. Kedraka (ed) (2016). Proceedings of the Symposium on University Pedagogy: Education and training in Higher Education, a terra incognita; 38-52. Alexandroupolis: Democritus University of Thrace. (in Greek)

Kordts-Freudinger, R. (2017). Feel, Think, Teach -Emotional Underpinnings of Approaches to Teaching in Higher Education. International Journal of Higher Education, 6(1), 217-229. https://doi.org/10.5430/ijhe.v6n1p217

Kreber, C., \& Cranton, P.A. (2000). Exploring the scholarship of teaching. Journal of Higher Education, 71, 476-496. https://doi.org/10.2307/2649149

Kreber, C. (2004). An analysis of two models of reflection and implications for educational development. International Journal for Academic Development, 9(1), 29-49. https://doi.org/10.1080/1360144042000296044

Kreber, C. (2005). Reflection on teaching and the scholarship of teaching: Focus on science instructors. Higher Education, 50, 323-359. https://doi.org/10.1007/s10734-004-6360-2

Labrianidis, L \& Vogiatzis, N. (2013). The mutually reinforcing relation between international migration of highly educated labour force and economic crisis: the case of Greece. Southeast European and Black Sea Studies, 13(4), 525-551. https://doi.org/10.1080/14683857.2013.859814

Lynch, P. R. \& Pappas, E. (2017). A Model for Teaching Large Classes: Facilitating a "Small Class Feel", International Journal of Higher Education, 6(2), 199-212. https://doi.org/10.5430/ijhe.v6n2p199

Mezirow, J. (1991). Transformative Dimensions of Adult Learning. San Francisco: Jossey - Bass.

Mezirow, J. (2009). An Overview on Transformative Learning. In: K. Illeris, (Ed.), Contemporary Theories of Learning. London and New York: Routledge, 90-105.

Oleson, A., \& Hora, M.T. (2014). Teaching the way they were taught? Revisiting the sources of teaching knowledge and the role of prior experience in shaping faculty teaching practices. Higher Education, 68, 29-45. https://doi.org/10.1007/s10734-013-9678-9

Pantano-Rokou, M.P., \& Sakellaridis, A. (2001). Didactic models for use in the University distance learning in net environment. Proceedings of 1st National Congress of Open and Distance Learning Education. Patras. (in Greek)

Pratt, D.D., \& Associates, (2005). Five perspectives on teaching in Adult and Higher Education. Malabar, FL: Krieger.

Pratt, D.D. (2002). Good teaching: One size fits all? New Directions for Adult and Continuing Education, 93, 5-16. https://doi.org/10.1002/ace.45

Prosser, M. \& Trigwell, K. (2014). Qualitative variation in approaches to university teaching and learning in large first-year classes. Higher Education: The International Journal for Higher Education and Educational Planning, 67, 783-795. https://doi.org/10.1007/s10734-013-9690-0 
Rossiou, E. (2010). Use of Information and Communications Technologies in synergy with e-learning and online collaborative learning for the implementation of Virtual Classes in Higher Education. Doctoral thesis. Thessaloniki: School of Applied Informatics- University of Macedonia. (in Greek).

Rotidi, G., \& Karalis, T. (2014). Reflection on Teaching in Higher Education, Critically reflective processes of Greek academics in Hard, Soft, Pure and Applied disciplines. Proceedings of the 1st Conference of ESREA's Network "Interrogating Transformative Processes in Learning and Education, An International Dialogue", 338-350. Athens, Greece, June, 2014.

Rotidi, G. (2016). Teaching perspectives and critically reflective processes of academics in higher education: a quantitative and qualitative research based on TPI (Teaching Perspectives Inventory), Biglan's taxonomy of academic disciplines and the SofT (Scholarship of Teaching) model. Doctoral thesis, University of Patras. (in Greek).

Rotidi, G., Collins, J.B., Karalis, T., \& Lavidas, K. (2017). Using the TPI to examine the relationship between teaching perspectives and disciplines in Higher Education. Journal of Further and Higher Education, 41(5), 611-624. https://doi.org/10.1080/0309877X.2016.1159289

Trigwell, K. (2012). Relations between teachers' emotions in teaching and their approaches to teaching in higher education, Instructional Science, 40(3), 607-621. https://doi.org/10.1007/s11251-011-9192-3

Weaver, R. R., \& Qi, J. (2005). Classroom organization and participation: College students' perceptions. The Journal of Higher Education, 76(5), 570-601. https://doi.org/10.1353/jhe.2005.0038

Winestone, N. \& Millard, L. (2012). Reframing perceptions of the lecture from challenges to opportunities: Embedding active learning and formative assessment into the teaching of large classes. Psychology Teaching Review, 18(2), 31-41. www.teachingperspectives.com

Zondanos, K. (2011). Report "Best Practices in Quality Assurance of Higher Education and Research". Under the ACT: MO.DI.P, University of Macedonia, Operational Program "Education and Lifelong Learning 2007-2013". Ministry of Education, Lifelong Learning and Religious Affairs. (in Greek).

\section{Notes}

Note 1. The Greek representative to the HLG was Professor Loukas Tsoukalis

Note 2. See www.teachingperspectives.com 